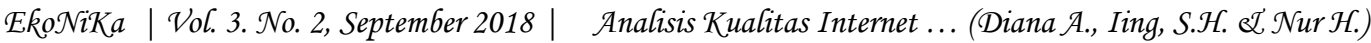
Doi: https://doi.org/10.30737/ekonika.v3i2.219

\title{
ANALISIS KUALITAS INTERNET MARKETING BERBASIS APLIKASI ANDROID "FEUNISKAMARKET"
}

\author{
Diana Ambarwati ${ }^{1}$ \\ Iing Sri Hardiningrum ${ }^{2}$ \\ Nur Hidayati ${ }^{3}$ \\ Prodi Manajemen Fakultas Ekonomi Universitas Islam Kadiri \\ dianaambarwati@uniska-kediri.ac.id \\ iingsriningsih@uniska-kediri.ac.id \\ nurhidayati@uniska-kediri.ac.id
}

\begin{abstract}
This study aims to analyze the quality of Internet Marketing based on the Android application "FEUNISKAMarket". This quantitative study conducted descriptive approach using the help of questionnaires in accordance with the research variable indicators. The process of dissemination and data collection is given randomly, sampling accidental non random probability non sampling by giving a questionnaire to 25 students who posted their products in the Android application "FEUNISKAmarket" and were willing to fill out questionnaires in May and June 2018. The results of this study indicate that all the most respondents are female students with the age range between 20 to 30 years as users of the Android Internet Marketing application "FEUNISKAmarket" stated agree and simply agree with the quality statement of the android application that has fulfilled aesthetic elements, user convenience, multimedia techniques and content that are interesting to see. However, disagree with the statement that the android application is already known by many people. It is expected that respondents can help socialize this android application to many people and researchers can then expand the population and sample if you want to examine the same variables and objects.
\end{abstract}

\section{Keyword : Quality of Internet Marketing Based on Android Applications}

\begin{abstract}
Abstrak
Penelitian ini bertujuan untuk menganalisis kualitas Internet Marketing berbasis aplikasi android "FEUNISKAMarket". Penelitian kuantitatif ini melakukan pendekatan secara deskriptif dengan menggunakan bantuan angket/kuesioner sesuai dengan indikator variabel penelitian. Proses penyebaran dan pengumpulan data diberikan secara acak yaitu sampling accidental non random probability non sampling dengan memberikan angket pada 25 mahasiswa yang memposting produknya di aplikasi android "FEUNISKAmarket" dan bersedia mengisi kuesioner pada bulan Mei dan Juni 2018. Hasil penelitian ini menunjukkan bahwa seluruh responden terbanyak yaitu mahasiswa perempuan dengan rentang umur antara $20 \mathrm{~s} / \mathrm{d} 30$ tahun sebagai pengguna aplikasi android Internet Marketing "FEUNISKAmarket" menyatakan setuju dan cukup setuju dengan pernyataan kualitas aplikasi android sudah memenuhi unsur estetika, kemudahan pengguna, teknik multimedia dan menu (konten) yang menarik untuk dilihat. Namun, tidak setuju dengan pernyataan bahwa aplikasi android sudah dikenal oleh banyak orang. Diharapkan responden dapat membantu mensosialisasikan aplikasi android ini pada banyak orang dan peneliti selanjutnya dapat memperluas populasi dan sampel jika ingin meneliti dengan variabel dan objek yang sama.
\end{abstract}

Kata Kunci: Kualitas Internet Marketing Berbasis Aplikasi Android 


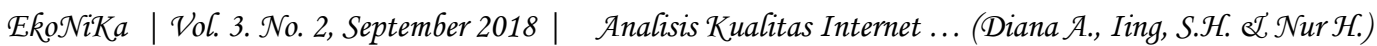
Doi: https://doi.org/10.30737/ekonika.v3i2.219

\section{PENDAHULUAN}

\section{Latar Belakang}

Saat ini untuk dapat melakukan kegiatan pemasaran, masyarakat didorong untuk memanfaatkan teknologi utamanya dibidang teknologi informasi. Kegiatan pemasaran dengan memanfaatkan teknologi informasi ini, dapat disebut sebagai sistem pemasaran online. Terdapat beberapa manfaat yang dapat diperoleh pada saat masyarakat memasarkan produknya dengan menggunakan sistem pemasaran online, diantaranya kecepatan akses, kemudahan pemesanan sampai dengan perputaran modal usaha.

Penelitian ini dimaksudkan untuk mengetahui seberapa besar kualitas Internet Marketing berbasis aplikasi android ini untuk meningkatkan penjualan produk mahasiswa Fakultas Ekonomi UNISKA. Penelitian ini juga diwujudkan dalam rangka tercapainya visi dan misi institusi dengan maksimal sehingga apa yang menjadi keinginan segenap civitas akademika dapat benar-benar mampu diterapkan dengan baik oleh seluruh mahasiswa.

Fakultas Ekonomi UNISKA juga telah mulai membantu memasarkan bermacam-macam produk buatan mahasiswanya dengan menggunakan sistem pemasaran online ini. Salah satu langkah yang digunakan adalah dengan memanfaatkan e-Commerce.

E-commerce atau electronic commerce hadir seiring dengan perkembangan internet yang sangat pesat. E-commerce menjadi daya tarik tersendiri bagi pecinta kegiatan belanja baik pria maupun wanita dalam menjawab tuntutan gaya hidup modern manusia yang menuntut kemudahan dan kecepatan dalam segala bidang. Tidak hanya pembeli yang dimudahkan dalam melakukan proses jual beli, penjual juga dimudahkan untuk menjual dengan mudah dan cepat dibandingkan menjual melalui toko offline.

Internet Marketing yang digunakan berbasiskan aplikasi android ini diberi nama FEUNISKAMarket. Aplikasi android ini mampu memperkenalkan produkproduk buatan mahasiswa. Hal ini akan lebih meningkatkan omset penjualan mahasiswa yang memiliki usaha dan tergabung menjadi member dari aplikasi Internet Marketing tersebut. Dengan pengaplikasian yang mudah, cukup dengan mendownload pada handphone yang dimiliki oleh hampir seluruh masyarakat. 


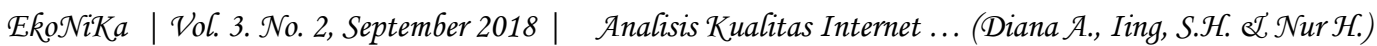
Doi : https://doi.org/10.30737/ekonika.v3i2.219

Harapan selanjutnya, kualitas dari aplikasi handphone dapat terus ditingkatkan sesuai dengan kebutuhan penggunanya sehingga tidak akan ditinggalkan baik penjual maupun penggunanya.

Berdasarkan latar belakang diatas, maka akan diadakan penelitian dengan judul "Analisis Kualitas Internet Marketing Berbasis Aplikasi Android FEUNISKAMarket".

\section{Rumusan Penelitian}

Bagaimana analisis kualitas Internet Marketing berbasis aplikasi android "FEUNISKAMarket"?

\section{Tujuan Penelitian}

Untuk menganalisis kualitas Internet Marketing berbasis aplikasi android "FEUNISKAMarket".

\section{Manfaat Penelitian}

1. Bagi Pelaku usaha, dapat mengetahui kebutuhan pengguna sebagai penjual produk dengan menggunakan aplikasi android.

2. Bagi Peneliti selanjutnya, dapat dipergunakan sebagai bahan referensi untuk melakukan penelitian lanjutan yang berkaitan dengan variabel.

3. Bagi Peneliti, dapat menambah wawasan dan pengetahuan, serta pengalaman yang berharga dalam menerapkan teori-teori yang diperoleh tentang kualitas Internet Marketing berbasis aplikasi android dan penjualan produk.

\section{TINJAUAN PUSTAKA}

\section{Sistem Informasi}

Kadir (2003) dalam (Sihotang, 2015) menyatakan sistem informasi merupakan sekumpulan elemen atau komponen yang terdiri dari manusia, komputer, teknologi informasi, dan prosedur kerja yang mengubah data menjadi informasi, dan dimaksudkan untuk mencapai suatu sasaran atau tujuan.

Sedangkan menurut Jogiyanto (2005) dalam (Sihotang, 2015) menyatakan sistem informasi adalah suatu sistem di dalam suatu organisasi yang mempertemukan kebutuhan pengelolaan transaksi harian, mendukung operasi, bersifat manajerial dan kegiatan strategi dari suatu organisasi dan menyediakan pihak luar tertentu dengan laporan-laporan yang diperlukan. 


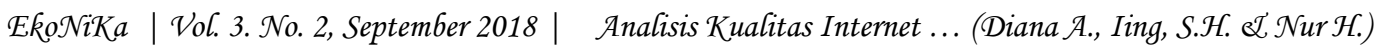
Doi : https://doi.org/10.30737/ekonika.v3i2.219

Internet Marketing

\section{(e-commerce)}

Karmawan (2010) dalam (Jauhari, 2010) menyatakan E-commerce adalah suatu jenis dari mekanisme bisnis secara elektronik yang memfokuskan diri pada transaksi bisnis berbasis individu dengan menggunakan internet (teknologi berbasis jaringan digital) sebagai medium pertukaran barang atau jasa baik antara dua buah institusi (business to business) dan konsumen langsung (business to consumer), melewati kendala ruang dan waktu yang selama ini merupakan hal-hal yang dominan. Dengan aplikasi e-commerce, hubungan antar perusahaan dengan entitas eksternal lainnya (pemasok, distributor, rekanan, konsumen) dapat dilakukan secara lebih cepat, lebih intensif, dan lebih murah daripada aplikasi prinsip manajemen secara konvensional (door to door, one-to-one relationship).

Teo (2006) dalam (Jauhari, 2010) menjelaskan salah satu media yang digunakan dalam e-Commerce adalah internet. Perkembangan media ini merupakan yang paling pesat dibandingkan dengan media lain dalam mendukung e-Commerce. Ada dua faktor pendukung yang menyebabkan internet berkembang lebih cepat dalam memediasi e-Commerce, yakni (1) internet memiliki jangkauan yang sangat luas, murah, cepat, dan mudah diakses oleh publik; (2) internet menggunakan elecronic data sebagai media penyampaian pesan/data sehingga dapat dilakukan pengiriman dan penerimaan informasi secara mudah dan ringkas, baik dalam bentuk data elektronik analog maupun digital.

\section{Penilaian Kualitas Aplikasi Android}

Singh (2014) menjelaskan kerangka penilaian sebuah website terdiri atas 5 (lima) karakteristik kualitas, diantaranya :

1. Estetika

2. Kemudahan penggunaan

3. Multimedia

4. Konten

5. Reputasi 


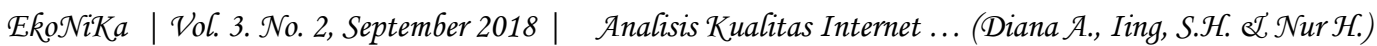
Doi: https://doi.org/10.30737/ekonika.v3i2.219

Kelima indikator tersebut dapat digunakan dalam menganalisis kualitas aplikasi Internet Marketing berbasis android.

\section{METODE PENELITIAN}

Penelitian kuantitatif ini menggunakan pendekatan secara deskriptif dengan menarik kesimpulan berdasarkan analisis kualitas Internet Marketing berbasis aplikasi android pada responden yang memasarkan produknya secara online. Pendekatan yang dilakukan dengan menggunakan alat bantu angket/kuesioner sesuai dengan indikator variabel. Proses penyebaran dan pengumpulan data diberikan secara acak pada mahasiswa yang memposting produknya pada saat pelaksanaan penelitian di bulan Mei dan Juni 2018 selama 2 (dua) bulan.

Populasi dalam penelitian ini adalah mahasiswa Fakultas Ekonomi UNISKA yang memiliki produk dan memasarkan produknya melalui aplikasi Internet Marketing "FEUNISKAmarket" dimulai pada bulan Maret 2018. Untuk mengadakan penelitian ini peneliti mengalami kesulitan jika harus menggunakan teknik penelitian populasi karena subjek penelitian yang menggunakan aplikasi ini tidak dapat ditentukan jumlahnya setiap hari dan tidak seluruh mahasiswa bersedia untuk mengisi kuesioner disebabkan kesibukan dan aktivitas yang dilakukan di lingkungan kampus. Untuk itu, peneliti menggunakan teknik pengambilan sampel sampling accidental non random probability non sampling dalam melakukan penelitian. Dengan memberikan angket pada mahasiswa yang memposting produknya di aplikasi "FEUNISKAmarket" pada saat dilaksanakannya penelitian. Teknik pengambilan sampel yang digunakan dalam penelitian ini adalah sampling accidental non random probability non sampling. Yaitu teknik penentuan sampel berdasarkan faktor spontanitas. Artinya siapa saja yang secara tidak sengaja bertemu dengan peneliti dan sesuai dengan karakteristik (ciri-cirinya) maka orang tersebut dapat digunakan sebagai sampel (responden) Ridwan (2004:62). Penyebaran dan pengambilan data dilakukan pada bulan Mei dan Juni 2018. 


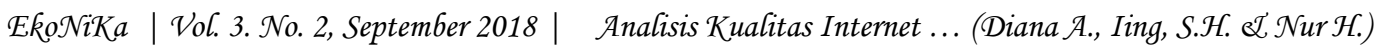
Doi: https://doi.org/10.30737/ekonika.v3i2.219

\section{HASIL PENELITIAN}

\section{Gambaran Karakteristik Responden}

\section{Karakteristik Mahasiswa Pengguna Aplikasi Android Berdasarkan Jenis}

\section{Kelamin}

Mahasiswa Fakultas Ekonomi UNISKA yang menggunakan aplikasi android Internet Marketing "FEUNISKAmarket" terdiri dari mahasiswa laki-laki dan perempuan. Berikut ini akan dijelaskan jumlah mahasiswa FE UNISKA yang menggunakan aplikasi ini dan bersedia mengisi kuesioner pada bulan Mei dan Juni 2018.

Tabel 1. Mahasiswa Pengguna Aplikasi Android Berdasarkan Jenis Kelamin

\begin{tabular}{clcc}
\hline No. & Jenis Kelamin & Frekuensi & Presentase \\
\hline 1. & Laki-laki & 5 & 20 \\
2. & Perempuan & 20 & 80 \\
\hline & Jumlah & $\mathbf{2 5}$ & $\mathbf{1 0 0}$ \\
\hline
\end{tabular}

Sumber : Data Primer Diolah (2018)

Dari tabel 1 diatas menunjukkan bahwa dari mahasiswa pengguna aplikasi android Internet Marketing terbukti mahasiswa perempuan lebih banyak menggunakan aplikasi Internet Marketing "FEUNISKAmarket" dengan jumlah frekuensi 20 orang atau $80 \%$ lebih banyak dibanding mahasiswa laki-laki.

\section{Karakteristik Mahasiswa Pengguna Aplikasi Android Berdasarkan Usia}

Mahasiswa Fakultas Ekonomi UNISKA yang menggunakan aplikasi android Internet Marketing "FEUNISKAmarket" berumur antara kurang dari 20 tahun s/d diatas 30 tahun. Berikut ini akan dijelaskan jumlah mahasiswa FE UNISKA yang menggunakan aplikasi ini dan bersedia mengisi kuesioner pada bulan Mei dan Juni 2018.

Tabel 2. Mahasiswa Pengguna Aplikasi Android Berdasarkan Usia

\begin{tabular}{cccc}
\hline No. & Jenis Kelamin & Frekuensi & Presentase \\
\hline 1. & $>20$ th & 9 & 36 \\
2. & $20-30$ th & 16 & 64 \\
3. & $<30$ th & 0 & 0 \\
& Jumlah & $\mathbf{2 5}$ & $\mathbf{1 0 0}$ \\
\hline
\end{tabular}

Sumber : Data Primer Diolah (2018)

Dari tabel 2 diatas menunjukkan bahwa dari mahasiswa pengguna aplikasi android Internet Marketing terbukti mahasiswa dengan umur antara 20 s/d 30 
EkoNiKa | Vol. 3. No. 2, September 2018 | Analisis Kualitas Internet ... (Diana A., Iing, S.H. \&. $\mathcal{N}$ ur $\mathcal{H}$.) Doi: https://doi.org/10.30737/ekonika.v3i2.219

tahun lebih banyak menggunakan aplikasi Internet Marketing "FEUNISKAmarket" dengan jumlah frekuensi 16 orang atau 64\% lebih banyak dibanding mahasiswa dengan umur kurang dari 20 tahun dan tidak terdapat mahasiswa dengan usia lebih dari 30 tahun.

Tanggapan Responden pada Angket Berdasarkan Identitas Responden

Tanggapan Responden Mahasiswa Laki-laki Pengguna tentang Kualitas Internet Marketing berbasis Aplikasi Android.

Tabel 3. Distribusi Jawaban Variabel Mahasiswa Laki-laki Pengguna tentang Kualitas Aplikasi Android PERNYATAAN

1. Komponen dalam aplikasi android ini (gambar,

$\begin{array}{lllll}\text { SS } & \text { S } & \text { CS } & \text { TS } & \text { STS }\end{array}$
menu dan warna) sudah memenuhi unsur estetika.

2. Menu-menu pada aplikasi android ini dapat digunakan dengan mudah karena menggunakan bahasa yang mudah dipahami.

3. Komponen dalam aplikasi android ini (gambar, $\begin{array}{lllllll}0 & 5 & 0 & 0 & 0\end{array}$ menu dan warna) menggunakan teknik multimedia.

4. Salah satu komponen aplikasi android ini menggunakan menu (konten) yang menarik untuk dilihat.

5. Aplikasi android ini sudah dikenal oleh banyak $\quad \begin{array}{lllllll}0 & 0 & 0 & 5 & 0\end{array}$ orang.

Sumber : Data Primer Diolah tahun (2018)

Dari variabel kualitas aplikasi android berdasarkan responden mahasiswa laki-laki pengguna diatas, responden laki-laki setuju dengan pernyataan kualitas aplikasi android sudah memenuhi unsur estetika, kemudahan pengguna, teknik multimedia dan menu (konten) yang menarik untuk dilihat. Namun, seluruh responden laki-laki tidak setuju dengan pernyataan bahwa aplikasi android sudah dikenal oleh banyak orang. 
EkoNiKa | Vol. 3. No. 2, September 2018 | Analisis Kualitas Internet ... (Diana A., Iing, S.H. ․ㅓ $\mathcal{N} u r \mathcal{H}$.) Doi: https://doi.org/10.30737/ekonika.v3i2.219

\section{Tanggapan Responden Mahasiswa Perempuan Pengguna tentang Kualitas}

Internet Marketing Berbasis Aplikasi Android.

\section{Tabel 4. Distribusi Jawaban Variabel Mahasiswa Perempuan Pengguna} tentang Kualitas Aplikasi Android

\begin{tabular}{|c|c|c|c|c|c|c|}
\hline & PERNYATAAN & SS & $\mathbf{S}$ & CS & TS & STS \\
\hline 1. & $\begin{array}{l}\text { Komponen dalam aplikasi android ini (gambar, } \\
\text { menu dan warna) sudah memenuhi unsur estetika. }\end{array}$ & 0 & 17 & 3 & 0 & 0 \\
\hline 2. & $\begin{array}{l}\text { Menu-menu pada aplikasi android ini dapat } \\
\text { digunakan dengan mudah karena menggunakan } \\
\text { bahasa yang mudah dipahami. }\end{array}$ & 0 & 20 & 0 & 0 & 0 \\
\hline 3. & $\begin{array}{l}\text { Komponen dalam aplikasi android ini (gambar, } \\
\text { menu dan warna) menggunakan teknik } \\
\text { multimedia. }\end{array}$ & 0 & 20 & 0 & 0 & 0 \\
\hline 4. & $\begin{array}{l}\text { Salah satu komponen aplikasi android ini } \\
\text { menggunakan menu (konten) yang menarik untuk } \\
\text { dilihat. }\end{array}$ & 0 & 5 & 15 & 0 & 0 \\
\hline 5. & $\begin{array}{l}\text { Aplikasi android ini sudah dikenal oleh banyak } \\
\text { orang. }\end{array}$ & 0 & 0 & 0 & 20 & 0 \\
\hline
\end{tabular}
Sumber : Data Primer Diolah (2018)

Dari variabel kualitas aplikasi android berdasarkan responden mahasiswa perempuan pengguna diatas, responden perempuan juga setuju dan cukup setuju dengan pernyataan kualitas aplikasi android sudah memenuhi unsur estetika, kemudahan pengguna, teknik multimedia dan menu (konten) yang menarik untuk dilihat. Namun, seluruh responden perempuan tidak setuju dengan pernyataan bahwa aplikasi android sudah dikenal oleh banyak orang.

\section{Tanggapan Responden Mahasiswa Berumur Kurang dari 20 Tahun} Pengguna tentang Kualitas Internet Marketing Berbasis Aplikasi Android.

Tabel 5. Distribusi Jawaban Variabel Mahasiswa Berumur Kurang dari 20 Tahun Pengguna tentang Kualitas Aplikasi Android

\begin{tabular}{|c|c|c|c|c|c|}
\hline PERNYATAAN & SS & $\mathbf{S}$ & CS & TS & STS \\
\hline $\begin{array}{l}\text { 1. Komponen dalam aplikasi android ini (gambar, } \\
\text { menu dan warna) sudah memenuhi unsur estetika. }\end{array}$ & 0 & 5 & 4 & 0 & 0 \\
\hline $\begin{array}{l}\text { 2. Menu-menu pada aplikasi android ini dapat } \\
\text { digunakan dengan mudah karena menggunakan } \\
\text { bahasa yang mudah dipahami. }\end{array}$ & 0 & 5 & 4 & 0 & 0 \\
\hline $\begin{array}{l}\text { 3. Komponen dalam aplikasi android ini (gambar, } \\
\text { menu dan warna) menggunakan teknik } \\
\text { multimedia. }\end{array}$ & 0 & 5 & 4 & 0 & 0 \\
\hline $\begin{array}{l}\text { 4. Salah satu komponen aplikasi android ini } \\
\text { menggunakan menu (konten) yang menarik untuk } \\
\text { dilihat. }\end{array}$ & 0 & 5 & 4 & 0 & 0 \\
\hline
\end{tabular}




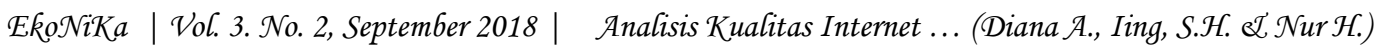
Doi: https://doi.org/10.30737/ekonika.v3i2.219

5. Aplikasi android ini sudah dikenal oleh banyak $\quad \begin{array}{llllll}0 & 0 & 0 & 9 & 0\end{array}$ orang.

Sumber : Data Primer Diolah (2018)

Dari variabel kualitas aplikasi android berdasarkan responden mahasiswa berumur kurang dari 20 tahun pengguna diatas, responden setuju dan cukup setuju dengan pernyataan kualitas aplikasi android sudah memenuhi unsur estetika, kemudahan pengguna, teknik multimedia dan menu (konten) yang menarik untuk dilihat. Namun, seluruh responden dengan umur kurang dari 20 tahun tidak setuju dengan pernyataan bahwa aplikasi android sudah dikenal oleh banyak orang.

\section{Tanggapan Responden Mahasiswa Berumur antara 20 s/d 30 Tahun}

Pengguna tentang Kualitas Internet Marketing Berbasis Aplikasi Android.

Tabel 6. Distribusi Jawaban Variabel Mahasiswa Berumur antara 20 s/d 30 Tahun Pengguna tentang Kualitas Aplikasi Android

\begin{tabular}{|c|c|c|c|c|c|}
\hline PERNYATAAN & SS & $\mathbf{S}$ & CS & TS & STS \\
\hline $\begin{array}{l}\text { 1. Komponen dalam aplikasi android ini (gambar, } \\
\text { menu dan warna) sudah memenuhi unsur } \\
\text { estetika. }\end{array}$ & 0 & 9 & 7 & 0 & 0 \\
\hline $\begin{array}{l}\text { 2. Menu-menu pada aplikasi android ini dapat } \\
\text { digunakan dengan mudah karena } \\
\text { menggunakan bahasa yang mudah dipahami. }\end{array}$ & 0 & 9 & 7 & 0 & 0 \\
\hline $\begin{array}{l}\text { 3. Komponen dalam aplikasi android ini (gambar, } \\
\text { menu dan warna) menggunakan teknik } \\
\text { multimedia. }\end{array}$ & 0 & 9 & 7 & 0 & 0 \\
\hline $\begin{array}{l}\text { 4. Salah satu komponen aplikasi android ini } \\
\text { menggunakan menu (konten) yang menarik } \\
\text { untuk dilihat. }\end{array}$ & 0 & 9 & 7 & 0 & 0 \\
\hline $\begin{array}{l}\text { 5. Aplikasi android ini sudah dikenal oleh banyak } \\
\text { orang. }\end{array}$ & 0 & 0 & 0 & 16 & 0 \\
\hline
\end{tabular}

Sumber : Data Primer Diolah (2018)

Dari variabel kualitas aplikasi android berdasarkan responden mahasiswa berumur antara $20 \mathrm{~s} / \mathrm{d} 30$ tahun pengguna diatas, responden setuju dan cukup setuju dengan pernyataan kualitas aplikasi android sudah memenuhi unsur estetika, kemudahan pengguna, teknik multimedia dan menu (konten) yang menarik untuk dilihat. Namun, seluruh responden dengan umur antara 20 s/d 30 tahun tidak setuju dengan pernyataan bahwa aplikasi android sudah dikenal oleh banyak orang. 


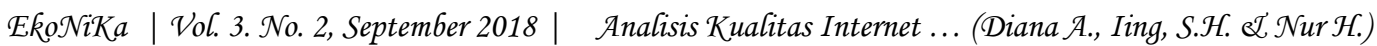
Doi: https://doi.org/10.30737/ekonika.v3i2.219

PEMBAHASAN

Berdasarkan hasil penelitian dan analisis data yang telah dilakukan maka dapat diketahui bahwa mahasiswa perempuan di Fakultas Ekonomi UNISKA lebih banyak menggunakan aplikasi android Internet Marketing "FEUNISKAmarket" dalam memasarkan produknya dengan jumlah frekuensi sebanyak 20 orang atau $80 \%$ lebih banyak dibanding mahasiswa laki-laki. Hal ini menunjukkan bahwa mahasiswa perempuan di Fakultas Ekonomi UNISKA cenderung tertarik menjadi pengusaha online dibandingkan offline. Hal ini juga dipengaruhi jumlah mahasiswa perempuan lebih banyak dibandingkan jumlah mahasiswa laki-laki secara keseluruhan.

Dilihat dari tanggapan responden berdasarkan identitas usia, maka dapat diketahui bahwa mahasiswa dengan umur antara 20 s/d 30 tahun lebih banyak menggunakan aplikasi Internet Marketing "FEUNISKAmarket" dengan jumlah frekuensi sebanyak 16 orang atau $64 \%$ lebih banyak dibanding mahasiswa dengan umur kurang dari 20 tahun. Sementara itu, tidak ada mahasiswa dengan umur diatas 30 tahun yang menggunakan aplikasi Internet Marketing tersebut. Mahasiswa dengan umur $20 \mathrm{~s} / \mathrm{d} 30$ tahun, lebih matang dan berpengalaman dalam bidang usaha dibanding dengan mahasiswa dengan umur kurang dari 20 tahun. Sementara itu, tidak adanya mahasiswa pengguna aplikasi ini dengan umur diatas 30 tahun disebabkan oleh sebagian besar mahasiswa dengan usia tersebut telah bekerja di perusahaan dan enggan untuk berwirausaha. Dapat ditarik kesimpulan bahwa mahasiswa perempuan dengan umur antara $20 \mathrm{sd} / 30$ tahun lebih banyak menggunakan aplikasi android Internet Marketing "FEUNISKAmarket".

Dilihat dari tanggapan mahasiswa laki-laki pengguna aplikasi android Internet Marketing tentang kualitas aplikasi android menyatakan seluruh responden laki-laki setuju dengan pernyataan kualitas aplikasi android sudah memenuhi unsur estetika, kemudahan pengguna, teknik multimedia dan menu (konten) yang menarik untuk dilihat. Namun, sebaliknya seluruh responden lakilaki tidak setuju dengan pernyataan bahwa aplikasi android sudah dikenal oleh banyak orang. Hal ini menunjukkan bahwa seluruh responden laki-laki tidak meyakini aplikasi android ini diketahui banyak orang terutama masyarakat secara umum. 


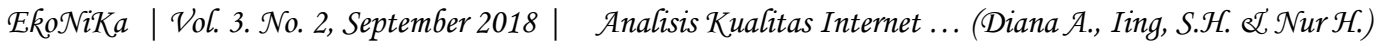
Doi : https://doi.org/10.30737/ekonika.v3i2.219

P-ISSN : 2502-9304

E-ISSN : $2581-2157$

Sementara itu, tanggapan mahasiswa perempuan pengguna aplikasi android Internet Marketing tentang kualitas aplikasi android menyatakan seluruh responden perempuan juga setuju dan cukup setuju dengan pernyataan kualitas aplikasi android sudah memenuhi unsur estetika, kemudahan pengguna, teknik multimedia dan menu (konten) yang menarik untuk dilihat. Namun sebaliknya, seluruh responden perempuan tidak setuju dengan pernyataan bahwa aplikasi android sudah dikenal oleh banyak orang. Hal ini menunjukkan bahwa tidak hanya responden laki-laki saja, responden perempuan juga meyakini aplikasi android ini belum dikenal masyarakat secara luas. Perlu adanya sosialisasi lebih luas selain pada seluruh civitas akademika, juga pada masyarakat Kediri dan sekitarnya agar mengetahui keberadaan aplikasi android ini.

Penelitian ini juga menganalisis tanggapan mahasiswa tentang kualitas aplikasi android dilihat dari sisi umur, responden mahasiswa pengguna aplikasi android dengan umur antara kurang dari 20 s/d 30 tahun menyatakan setuju dan cukup setuju dengan pernyataan kualitas aplikasi android sudah memenuhi unsur estetika, kemudahan pengguna, teknik multimedia dan menu (konten) yang menarik untuk dilihat. Namun, seluruh responden dengan umur tersebut tidak setuju dengan pernyataan bahwa aplikasi android sudah dikenal oleh banyak orang. Hal ini menunjukkan mahasiswa dengan umur antara kurang dari 20 s/d 30 tahun juga tidak meyakini aplikasi android ini diketahui oleh banyak orang.

Aplikasi android yang digunakan untuk memasarkan produk ini memang sangat bergantung pada kelima kualitas website. Kelima kualitas website tersebut terdiri dari unsur estetika, kemudahan pengguna, teknik multimedia, konten dan reputasi. Jika komponen dalam website yang terdiri dari gambar, menu dan warna yang disediakan terlihat estetik atau indah dengan menggunakan teknik multimedia dan konten yang menarik, maka pengguna baik laki-laki maupun perempuan dengan rentang umur kurang dari 20 sampai dengan 30 tahun bahkan lebih, tak segan-segan untuk sering melihat bahkan memanfaatkan untuk memuaskan kebutuhannya sehingga tercapailah tujuan dibuatnya aplikasi android ini. Begitu juga, kemudahan penggunaan aplikasi android dimana bahasa yang digunakan pada setiap menunya mudah untuk dipahami, tentu hal ini juga yang diinginkan oleh pengguna. Tak hanya itu, jika aplikasi android ini sering 


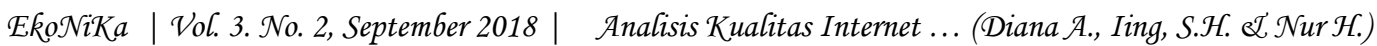
Doi : https://doi.org/10.30737/ekonika.v3i2.219

disosialisasikan, maka ke depan aplikasi android ini semakin sering didownload oleh pengguna. Untuk semakin memperluas, hasil penelitian ini ke depan, sampel yang digunakan dapat diperluas dengan mengambil pengguna selain mahasiswa yang memasarkan produknya saja tetapi juga pengguna yang mengkonsumsi produk yang terjual pada aplikasi android.

\section{KESIMPULAN}

Seluruh responden terbanyak yaitu mahasiswa perempuan dengan rentang umur antara $20 \mathrm{~s} / \mathrm{d} 30$ tahun sebagai pengguna aplikasi android Internet Marketing "FEUNISKAmarket" menyatakan setuju dan cukup setuju dengan pernyataan kualitas aplikasi android sudah memenuhi unsur estetika, kemudahan pengguna, teknik multimedia dan menu (konten) yang menarik untuk dilihat. Namun, tidak setuju dengan pernyataan bahwa aplikasi android sudah dikenal oleh banyak orang.

\section{SARAN}

1. Bagi Responden

Membantu mensosialisasikan aplikasi android "FEUNISKAMarket" sehingga dikenal oleh masyarakat secara luas.

2. Bagi Peneliti Selanjutnya

Memperluas populasi dan sampel guna meningkatkan kualitas penelitian dengan variabel yang sama.

3. Bagi Peneliti

Menambah wawasan dan pengetahuan serta pengalaman utamanya tim peneliti dalam menganalisis kualitas Internet Marketing berbasis aplikasi android.

\section{DAFTAR PUSTAKA}

Jauhari, Jaidan, Upaya Pengembangan Usaha Kecil Dan Menengah (UKM) dengan Memanfaatkan E-Commerce, Jurnal Sistem Informasi (JSI), VOL. 2, NO. 1, April 2010 : 159-168. Fakultas Ilmu Komputer Universitas Sriwijaya.

Jogiyanto, HM. (2005). Sistem Teknologi Informasi. Yogyakarta: ANDI. 
EkoNiKa | Vol. 3. No. 2, September 2018 | Analisis Kualitas Internet ... (Diana A., Iing, S.H. $\mathcal{L}$ ( $\mathcal{N} u r \mathcal{H}$.) Doi: https://doi.org/10.30737/ekonika.v3i2.219

Kadir, Abdul. (2003). Pengenalan Sistem Informasi. Yogyakarta: ANDI.

Karmawan, I.G.M dkk. (2010). Analisis Dan Perancangan E-Commerce Pd. Garuda Jaya. Makalah disampaikan pada Seminar Nasional Aplikasi Teknologi Informasi 2010 (SNATI 2010).

Teo, T.S.H., Ranganathan, C.\& Dhaliwal, J. (2006). Key Dimensions of Inhibitors for the Deployment of Web-Based Business-to-Business Electronic Commerce, IEEE Transactions on Engineering Management August 2006.

Singh, Kavindra Kumar. (2014). Implementation of a Model for Websites Quality Evaluation-DU Website. International Journal of Innovations \& Advancement in Computer Science. Volume 3, Issue 1. 